\title{
ANESTHETIC MANAGEMENT OF AN ANEMIC PARTURIENT WITH SEVERE KYPHOSCOLIOSIS AND BILATERAL POLIOMYELITIS FOR EMERGENCY CAESAREAN SECTION
}

\author{
Sujay Mysore ${ }^{1}$, Laxmi Priyanka Karri², Merajuddin S3, Venugopalan V. M4, Raghunath Ravirala ${ }^{5}$
}

\section{HOW TO CITE THIS ARTICLE:}

Sujay Mysore, Laxmi Priyanka Karri, Merajuddin S, Venugopalan V. M, Raghunath Ravirala. "Anesthetic Management of an Anemic Parturient with Severe Kyphoscoliosis and Bilateral Poliomyelitis for Emergency Caesarean Section". Journal of Evolution of Medical and Dental Sciences 2014; Vol. 3, Issue 20, May 19;

Page: 5461-5466, DOI: 10.14260/jemds/2014/2614

ABSTRACT: Anesthesia for emergency caesarean section for a pregnant patient with severe dorsolumbar kyphoscoliosis and severe anemia is associated with potential risks for both mother and the fetus due to alterations in maternal physiology and the pathological changes associated with kyphoscoliosis. In an emergency situation, the anesthesiologist has to quickly choose the anesthetic technique depending on the cardiopulmonary status of the patient and feasibility. We present a case of a 20 year old parturient in labour with severe kyphoscoliosis and severe anemia who was posted for emergency caesarean section. In view of severe anemia, anticipated technical difficulties with central neuraxial blocks and emergency situation, she was administered general anesthesia (GA) with uneventful recovery.

KEYWORDS: Severe kyphoscoliosis, bilateral poliomyelitis, severe anemia, pregnancy, general anesthesia.

INTRODUCTION: Kyphoscoliosis is characterized by progressive deformity of the spine consisting of lateral and posterior curvatures. It can be idiopathic $(80 \%)^{1}$ or secondary. One of the major causes of secondary kyphoscoliosis in India is poliomyelitis. The incidence of kyphoscoliosis complicating pregnancy is $0.072 \% .^{2}$ According to World Health Organisation, anemia in pregnancy is considered severe $^{3}$ when hemoglobin is less than $7 \mathrm{~g} / \mathrm{dl}$. Restrictive lung disease associated with kyphoscoliosis and severe anemia imposes an exaggerated load on compromised cardiopulmonary status in a parturient.

CASE HISTORY: A 148 centimeter, 40 kilogram, 20 years old unbooked primigravida with severe kyphoscoliosis and bilateral poliomyelitis since childhood presented in labor at 37 weeks of pregnancy. She was posted for emergency caesarean section in view of cephalopelvic disproportion in labor. No history of effort intolerance throughout childhood or pregnancy. On examination, she was conscious and oriented with severe pallor. Bilateral fixed flexion deformity of the lower limbs was present. Pulse rate 98/min, Blood Pressure 140/86 mm Hg, Respiratory rate (RR) 18/min, temperature 38 degrees celsius, Sp02 99\% on room air.

Airway assessment revealed Mallampatti grade II with full range of neck movements. On systemic examination, thorax was asymmetric with severe dorsolumbar kyphoscoliosis at the level of T7 to L4 spine and Intervertebral spaces were palpable in the loin. Cervical spine was normal, Chest was clear with decreased breath sounds over the right infrascapular area. Breath holding time was 15 seconds. Cardiovascular system was normal. Her investigations were hemoglobin $4.5 \mathrm{~g} / \mathrm{dl}$, total 
leukocyte count, bleeding time, clotting time, platelets, renal profile, arterial blood gas analysis (ABG) and electrocardiography (ECG) were within normal limits.

Central nervous system examination revealed muscle power of $3 / 5$ in the lower limbs. Preoperative pulmonary function tests, 2D echo, chest X-ray were not done in view of emergency. As the patient was severely anemic with severe kyphoscoliosis and in labor, GA was considered for emergency caesarean section. The various anesthetic options were discussed with the patient and an informed consent was taken to administer GA under ASA III.

Two 18G cannula were secured, continuous monitoring of ECG, non-invasive blood pressure, pulse oximetry, end tidal carbon dioxide were done. Difficult airway cart was ready. Preoxygenation was done with $100 \%$ oxygen (02) for 3 minutes, premedicated with injection glycopyrrolate $0.004 \mathrm{mg} / \mathrm{kg}$ intravenous (IV), injection ranitidine $1 \mathrm{mg} / \mathrm{kg}$, injection metoclopramide $0.15 \mathrm{mg} / \mathrm{kg}$ IV.

Rapid sequence induction was done with injection thiopentone sodium $5 \mathrm{mg} / \mathrm{kg}$ IV and injection rocuronium $0.8 \mathrm{mg} / \mathrm{kg}$ IV. Intubation response was attenuated with injection xylocard $1.5 \mathrm{mg} / \mathrm{kg}$ IV. Endotracheal intubation was done with $6.5 \mathrm{~mm}$ cuffed tube and airway secured. Anesthesia was maintained with 026 litres/minute, isoflurane $0.2-0.4 \%$.

Induction delivery time was 8 minutes. A $2.5 \mathrm{~kg}$ male child with APGAR score 7 at 1 minute and 9 at 3 minutes was delivered. After delivery of the baby oxytocin 20 units, Injection midazolam $1 \mathrm{mg}$ and injection fentanyl $40 \mu \mathrm{g}$ IV were given. Intraoperatively, vitals were stable. Two units of packed red cells were transfused. The patient was electively ventilated post operatively for 2 hours, extubated according to standard criteria.

Urine output was $1 \mathrm{ml} / \mathrm{kg} /$ hour. Postoperative analgesia was provided with IV fentanyl infusion at the rate of $12.5 \mu \mathrm{g} /$ hour for the first $4 \mathrm{hrs}$. followed by injection diclofenac sodium $75 \mathrm{mg}$ intramuscularly twice daily. Postoperative ABG before and after extubation were normal, haemoglobin was $7 \mathrm{~g} / \mathrm{dl}$. X -ray chest, CT scan and 2D echo were done on first postoperative day to assess the severity of kyphoscoliosis. Chest physiotherapy and deep breathing exercises were given. Her vitals were stable throughout the postoperative period and she was discharged on the tenth day.

DISCUSSION: An important focus in obstetric surgery is the safe and skilled anaesthetic management to minimize risk to the mother and the fetus. For an emergency caesarean section in a patient with severe kyphoscoliosis who has severe anaemia with a full stomach the choice of anaesthesia is important. The physiological changes in pregnancy can worsen the respiratory function in a scoliotic patient with restrictive lung disorder.

Poliomyelitis is associated with scoliosis in $30 \%$ of patients when compared to its prevalence in general population which is $0.3-15.3 \% .{ }^{4}$ Kyphoscoliosis is graded by measuring Cobb's angle and classified as mild (11-25 degrees), moderate (25-50degrees), or severe ( $>50$ degrees). ${ }^{5}$ The Cobb's angle can be correlated with the pulmonary function tests where Cobb's angle above 60 degrees is associated with progressive pulmonary and cardiac failure. ${ }^{6}$ Pregnancy may further exacerbate both the severity of spinal curvature and cardiorespiratory abnormalities in patients with uncorrected scoliosis. ${ }^{7}$ In our case, though the Cobb's angle was 72 degrees she did not have any symptoms of decreased cardiorespiratory reserve and could tolerate pregnancy.

During pregnancy, increased minute volume is by increase in tidal volume rather than RR. In midgestation, diaphragmatic activity is restricted as the enlarging uterus enters the abdominal cavity thus decreasing functional residual capacity (FRC) and closing capacity (CC). In kyphoscoliosis with 
restrictive pattern, rise in tidal volume is not possible and the increased minute volume is achieved by increased RR resulting in increased work of breathing and oxygen consumption. Decrease in FRC and CC more than the anticipated values result in ventilation perfusion mismatch and reduced arterial oxygen content. In our case with severe anemia the oxygen supply was expected to be less.

The anesthetic goal was directed towards minimizing factors interfering with 02 delivery, prevent any increase in 02 consumption and to optimize the partial pressure of 02 in the arterial blood by avoiding hypoxia, minimising drug induced decrease in cardiac output by preventing bradycardia and hypotension.

Monitoring should be aimed at assessing the adequacy of perfusion and oxygenation of vital organs which includes monitors like ECG, non-invasive blood pressure, end tidal carbon dioxide, temperature, pulse oximetry, urine output and ABG analysis.

Preoperative blood transfusion was not possible as it was an emergency, but we gathered adequate units of packed red cells before induction. Hypothermia was avoided by infusing warm intravenous fluids and blood. Aspiration prophylaxis was given, rapid sequence induction was done. In view of polio, succinylcholine was avoided to prevent hyperkalemia. ${ }^{8}$

The different choices regarding the type of anaesthesia were General anaesthesia, spinal, continuous spinal, epidural or combined spinal epidural. Central neuraxial blocks are advantageous in providing good analgesia, ability to provide supplemental 02 and reduced blood loss. However, pitfalls with central neuraxial blocks include dangers of hypotension, subsequent heart failure or pulmonary oedema on the return of vascular tone ${ }^{9}$, unsuccessful or multiple attempts for insertion, false loss of resistance, dural puncture, failed block or inadequate analgesia. ${ }^{10}$

In severe kyphoscoliosis, there is decreased volume of cerebrospinal fluid and even lower volumes of local anaesthetic drug can produce higher level than expected. ${ }^{11}$ Systemic hypotension consequent to a regional block could have worsened the existent maternal decompensation.

GA was administered in this patient to avoid technical difficulty with regional, maternal decompensation associated with severe anaemia and due to emergency surgery, but disadvantages with GA like increase in pulmonary artery pressure leading to right heart failure, decrease in venous return and cardiac output with positive pressure ventilation were minimised. Postoperatively anticipating delayed recovery patient was ventilated for 2 hours.

CONCLUSION: Pregnancy along with kyphoscoliosis presents a unique challenge to the anesthesiologist which worsens when associated with severe anaemia, GA is preferable as it provides airway control and adequate oxygenation. Regional anaesthesia is widely practised but has limitations due to technical difficulty. In our case, anatomic deformity was much severe than physiologic abnormality.

\section{REFERENCES:}

1. Korula S, Ipe S, Saramma SP. Parturient with severe kyphoscoliosis: An anesthetic challenge. J Obstet Anaesth Crit Care. 2011; 1: 81-4.

2. Chopra S, Adhikari K, Agarwal N, Suri V, Sikka P. Kyphoscoliosis complicating pregnancy: Maternal and neonatal outcome. Arch Gynecol Obstet. 2011;284:295-97.

3. Grewal A. Anaemia and pregnancy: Anaesthetic implications. Indian J Anaesth. 2010; 54: 380-6.

4. Kumari BG, Samantaray A, Kiran Kumar VA, Durga P, Jagadesh G. Spinal anaesthesia in 
poliomyelitis patients with scoliotic spine: A case control study. Indian J Anaesth 2013; 57:145-9.

5. C. Bowens, K.H. Dobie, C. J. Devin and J. M. Corey. An approach to neuraxial anaesthesia for the severely scoliotic spine. BJA Advance Access 2013. doi:10.1093/bja/aet161.

6. Veliath DG, Sharma R, Ranjan RV, Rajesh Kumar CP, Ramachandran TR. Parturient with kyphoscoliosis (operated) for caesarean section. J Anaesth Clin Pharmacol. 2012; 28:124-6.

7. Kahler C M, Hogl B, Habeler R, Brezinka C, Hamacher J, Dienstl A. Management of respiratory deterioration in a pregnant patient with severe kyphoscoliosis by non-invasive positive pressure ventilation. Wien Klin Wochenshr 2002; 114:874-7.

8. Werner Klingler, Frank Lehmann-Horn, Karin Jurkat-Rott. Complications of anaesthesia in neuromuscular disorders. Neuromuscular disorder. 2005; 15:195-206.

9. Basu SM. Anaemia and Pregnancy. In: Gupta S, editor. Obstetric Anaesthesia. 1st ed. Delhi: Arya Publications; 2004. p. 433-56.

10. Dinesh K, Ravi M, Ramesh Kumar PB, Krishna Kumar BR, Kishore KS, Somasekharam P. Severe thoraco lumbar kyphoscoliosis- a challenge to anaesthesiologists. Int J Pharm Biomed Res 2012; 3(1): 69-70

11. Madhavi U Santpur, Unmesh Santpur, PV Saisathyanarayana, VM Venogopalan, Ananth Reddy. Spinal Anaesthesia for a Severe Kyphoscoliotic Parturient - A Challenge. The Indian Anaesthetists' Forum. April 2014; 15(4): 1-5

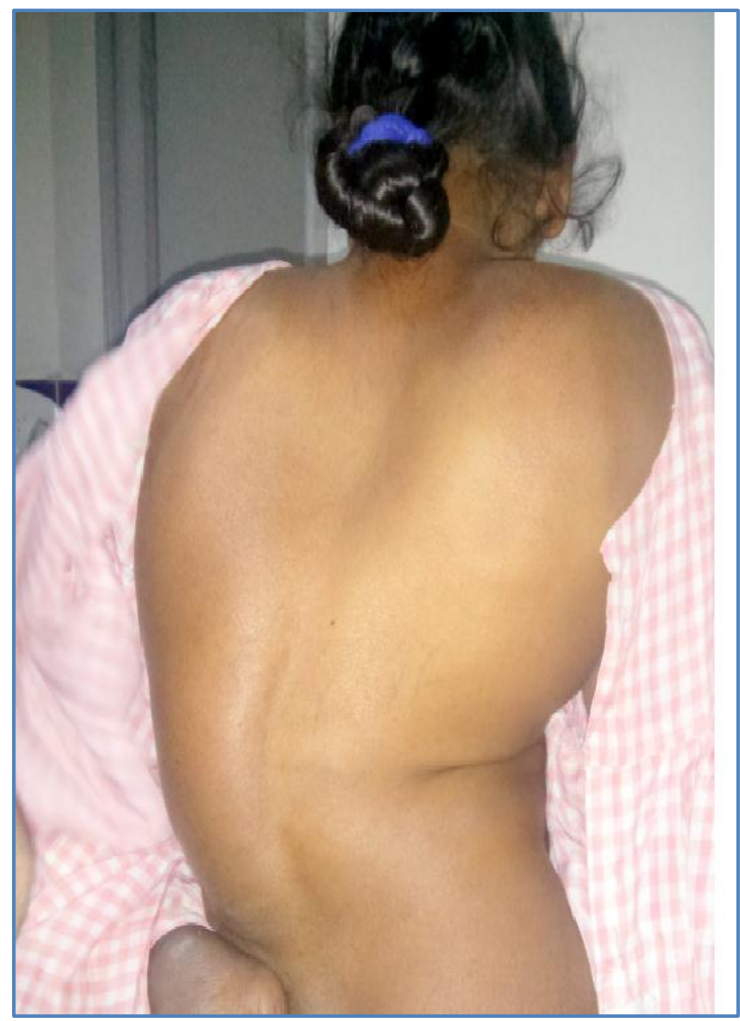

Fig. 1: Picture of Patient back showing deformity 


\section{CASE REPORT}

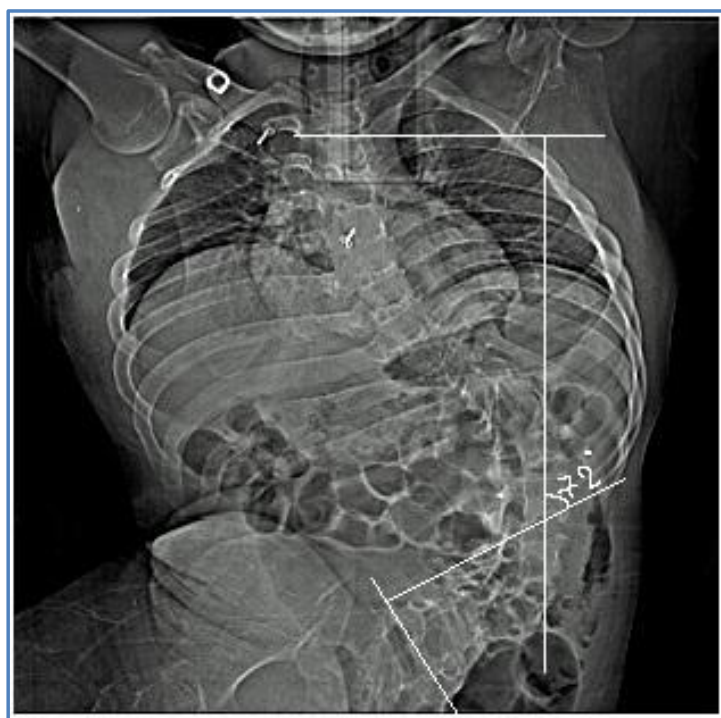

Multiplanner reconstruction image showing scoliosis

\section{Figure 2}

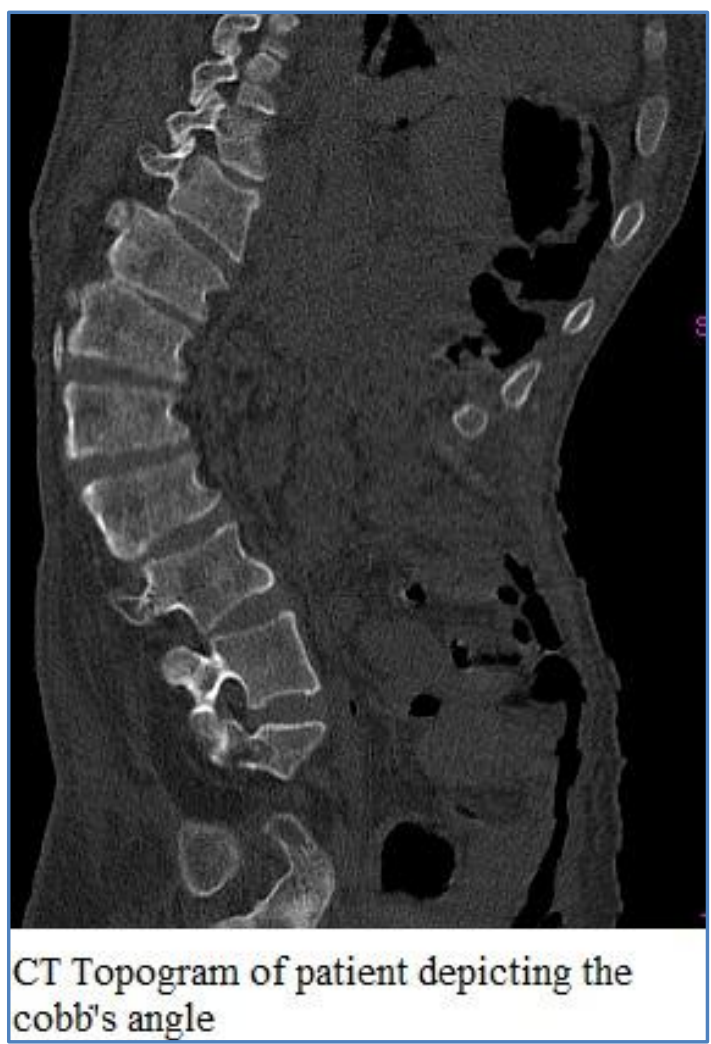

\section{Figure 3}




\section{CASE REPORT}

\section{AUTHORS:}

1. Sujay Mysore

2. Laxmi Priyanka Karri

3. Merajuddin S.

4. Venugopalan V. M.

5. Raghunath Ravirala

\section{PARTICULARS OF CONTRIBUTORS:}

1. Assistant Professor, Department of Anaesthesiology, Kamineni Institute of Medical Sciences, Narketpally.

2. Post Graduate, Department of Anaesthesiology, Kamineni Institute of Medical Sciences, Narketpally.

3. Post Graduate, Department of Anaesthesiology, Kamineni Institute of Medical Sciences, Narketpally.

4. Professor, Department of Anaesthesiology, Kamineni Institute of Medical Sciences, Narketpally.
5. Post Graduate, Department of Anaesthesiology, Kamineni Institute of Medical Sciences, Narketpally.

\section{NAME ADDRESS EMAIL ID OF THE} CORRESPONDING AUTHOR:

Dr. Sujay M,

\#1-14-158,

Balamrai, 68, Sappers Lines,

Secunderabad - 500003.

Email: drsujaym@gmail.com

Date of Submission: 25/04/2014.

Date of Peer Review: 26/04/2014.

Date of Acceptance: 30/04/2014.

Date of Publishing: 15/05/2014. 